\title{
The Etiological Profile of Serofibrinous Pleurisy
}

\author{
Zaghba Nahid ${ }^{1}$, Dr. Zerraa Mariem ${ }^{2 *}$, Dr. Farissi Chaimaa ${ }^{2}$, Benjelloun Hanane ${ }^{1}$, Chaanoun Khadija ${ }^{1}$, Yassine Najiba $^{1}$
}

${ }^{1}$ Professor, Department of Respiratory Diseases, CHU Ibn Rochd, Casablanca, Morocco

${ }^{2}$ Department of Respiratory Diseases, CHU Ibn Rochd, Casablanca, Morocco

\author{
DOI: $10.36347 /$ sasjm.2021.v07i03.007 \\ | Received: 27.02.2021 | Accepted: 11.03.2021 | Published: 28.03.2021 \\ *Corresponding author: Zerraa Mariem
}

Abstract

Original Research Article

Serofibrinous pleurisy is a very common pathology in pulmonology with multiple etiologies. We report a descriptive retrospective study about 1471 cases of serofibrinous pleurisy collected from the respiratory diseases department of the Ibn Rochd University Hospital Center in Casablanca, spanning 7 years from 2013 to 2019, the main objective of which is to determine the etiological profile of serofibrinous pleurisy. These were 853 men (58\%) versus 618 women (42\%) with an average age of 50 years (16 to 95 years). Active smoking and a history of neoplasia were found in $34 \%$ of cases each, a history of tuberculosis was noted in $20 \%$ of cases and connectivitis in 31 patients. The clinical symptomatology was dominated by chest pain (87\%). Fluid effusion syndrome was found in $86 \%$ of cases. Chest $\mathrm{x}-$ ray showed pleurisy of moderate abundance in $71 \%$, high abundance in $17 \%$ and low abundance in $12 \%$ of cases. The etiological diagnosis was confirmed by a pleural biopsy puncture in $65 \%$ of cases and by thoracoscopy in $7 \%$ of cases. Etiologies were dominated by tuberculosis in $56 \%$ of cases followed by malignant etiology in $31 \%$ and systemic disease in $3 \%$ of cases. The etiology was not determined in $9 \%$ of cases. Treatment depends on the etiology. The course was good in $64 \%$ of cases. Through this study, we are emphasizing the value of pleural biopsy puncture in the etiological diagnosis of serofibrinous pleurisy and on the frequency of the tuberculous origin which remains the most frequent etiology in our context, followed by the neoplastic origin.

Keywords: Serofibrinous pleurisy, tuberculosis, etiology.

Copyright $\odot 2021$ The Author(s): This is an open-access article distributed under the terms of the Creative Commons Attribution 4.0 International License (CC BY-NC 4.0) which permits unrestricted use, distribution, and reproduction in any medium for non-commercial use provided the original author and source are credited.

\section{INTRODUCTION}

Serofibrinous pleurisy is a citrus-yellow fluid effusion, of the exudative type, rich in albumin and fibrin, of variable cytological composition, linked to acute or chronic inflammation of the pleura [1]. It is a very common pathology in pneumology with multiple etiologies. In Europe, cancer is the most common etiology in the elderly. In Africa, the endemic nature of tuberculosis contemplates a different etiological profile dominated by tuberculosis, Ndongo et al., 2009; Dagran et al., 2004; Diallo et al., 2006.

The diagnosis of serofibrinous pleurisy does not pose practically any problem, and it is most often based on the clinical examination and the chest X-ray but the etiology is sometimes difficult to specify despite the panoply of examinations and investigations that can be carried out [2].

In Morocco, serofibrinous pleurisy is a frequent reason for consultation in clinical practice but it poses a problem of etiological diagnosis, hence the interest of our study which aims to describe the etiological profile of serofibrinous pleurisy.

\section{MATERIAL AND METHODS}

This is a descriptive retrospective study about 1471 cases of serofibrinous pleurisy collected in the respiratory diseases department of the Ibn Rochd University Hospital Center in Casablanca spanning 7 years from 2013 to 2019 and which was conducted on the basis of medical records.

We included in our study all the patients who presented signs in favor of fluid effusion on clinical examination and / or on standard chest radiography and who had benefited from a pleural puncture bringing back serofibrinous fluid: citrus yellow fluid, rich in proteins (protein rate greater than $30 \mathrm{~g} / \mathrm{l}$ ). All patients with transudative, serohematical, chylous and frankly purulent pleural effusions were excluded.

For each patient, we completed a survey form which enabled us to collect epidemiological data (age, sex), personal and family history (smoking, tuberculosis 
contagion, history of tuberculosis, cancer or system disease, etc), clinical signs, radiological images, means of etiological confirmation, as well as the treatment received and the course. Data was entered and analyzed using Microsoft Excel For Mac 2011.

\section{RESULTS}

During the study period, 1,471 cases of patients followed for serofibrinous pleurisy were collected in the department. This number represents $21 \%$ of all patients hospitalized during this period and $74 \%$ of cases admitted for pleurisy in any aspect.

The ages ranged from 16 to 95 years, with an average age of 50. Male predominance was noted in $58 \%$, while women accounted for $42 \%$ of cases. The majority of our patients were of low socioeconomic level in $71 \%$ of cases. Of the 1471 cases, $21 \%$ of the patients lived in slums (zinc roofs), $43 \%$ lived in poorly sunny and poorly ventilated apartments and $32 \%$ lived in rural areas.

Active smoking was noted in 501 patients (34\%) of which 407 were male. Passive smoking was found in 220 patients (15\%), while 750 of our patients $(51 \%)$ had no toxic habit. A history of tuberculosis was noted in 290 patients $(20 \%)$, tuberculosis contagion was found in 250 patients (17\%). The questioning found a history of neoplasia in 496 of our patients (34\%) (of which lung and breast cancer were predominant in 269 and 116 cases respectively), diabetes in 250 patients (17\%), occupational exposure asbestos in 132 patients $(9 \%)$ and silica in 90 patients $(6 \%)$, arterial hypertension in 117 patients $(8 \%)$ and connectivitis in 31 patients (13 of whom were followed for rheumatoid arthritis, ten for lupus and eight for scleroderma) (Table-1).

The clinical signs were dominated by basal thoracic pain in $87 \%$ of cases, dry cough in $83 \%$ of cases and dyspnea in $65 \%$ of cases. The majority of our patients presented general signs dominated by febrile sensations in $67 \%$ of cases and weight loss in $52 \%$ of cases. The clinical examination on admission found fluid effusion syndrome in $86 \%$ of cases associated with contralateral snoring rales in $11 \%$ of cases and peripheral lymphadenopathy in $13 \%$ of cases.

The chest $x$-ray was performed in all of our patients and found pleural-type opacity in $89 \%$ of cases (Figure-1), opaque hemithorax in $6 \%$ of cases, opacity in favor of encysted pleurisy in $3 \%$ cases and blunt cul de sac in $2 \%$ of cases. Pleural effusion was judged to be of moderate abundance in $71 \%$ of cases, of high abundance in $17 \%$ of cases and of low abundance in $12 \%$ of cases. The serofibrinous pleurisy was unilateral in $91 \%$ of cases and bilateral in $9 \%$ of cases. The unilateral pleurisy was located on the right in $61 \%$ of cases and on the left in $39 \%$ of cases.
Chest ultrasound, performed in $39 \%$ of patients, demonstrated low abundance pleurisy in $12 \%$ of cases, high abundance and encysted in $6 \%$ of cases each. Thoracic CT performed in $52 \%$ of our patients showed moderate abundance in $45 \%$ of cases and high abundance in $4 \%$ of cases associated with a tumor process (14\%) (Figure-2), pleural thickening (16\%), mediastinal lymphadenopathy $(7 \%)$, atelectasis $(5 \%)$, interstitial syndrome and pachypleuritis in $3 \%$ each. Intradermal reaction to tuberculin carried out in 1074 patients $(73 \%)$ returned positive in 693 cases $(47 \%)$.

All of our patients underwent exploratory pleural puncture. It removed fluid $97 \%$ of the time and was white in $3 \%$ of the cases. The fluid was Citrus Yellow in $89 \%$ and Light Yellow in $8 \%$ of the cases. The albumin level varied between $30 \mathrm{~g} / 1$ and $91 \mathrm{~g} / \mathrm{l}$ with an average of $48 \mathrm{~g} / 1$. The LDH assay performed in $25 \%$ of patients was greater than $200 \mathrm{U} / 1$ in $24 \%$ of cases. Lymphocytosis was found in $94 \%$ of cases, the rate of lymphocytes varied between $60 \%$ and $99 \%$ with an average rate of $83 \%$. A predominance of polynuclear neutrophils (PNN) was found in 13 cases. The presence of neoplastic cells was noted in $6 \%$ of cases and the search for blasts in pleural fluid was positive in seven cases. The dosage of rheumatoid factor in pleural fluid was elevated in seven cases and anti-nuclear antibodies were positive in nine cases.

In our study, 1433 patients $(97 \%)$ underwent a pleural biopsy biopsy which confirmed the diagnosis in 936 cases (65\%). Bronchoscopy performed in 401 patients $(27 \%)$ showed tumor-like infiltration in 75 cases $(19 \%)$, extrinsic compression in 58 cases $(14 \%)$, bronchial granulations associated with thickening of the spurs in 52 cases (13\%), a reduction in the size of the orifices in 44 cases $(11 \%)$, a budding tumor in 40 cases $(10 \%)$ (Figure-3) and a tumor-like stenosis in 39 cases (10\%). Thoracoscopy performed in 104 patients (7\%) showed tumor nodular aspects suggestive of neoplasia in 52 cases, diffuse pleural thickening with association of metastatic invading islands in 43 cases, whitish granulations covering the parietal and diaphragmatic pleura in five cases, and calcified fibrohyaline parietal pleural plaques in four cases.

The a etiological diagnostic confirmation was obtained by puncture biopsy pleural in 936 cases (65\%), bronchial biopsies in 217 cases $(15 \%)$ and thoracoscopy in 104 cases $(7 \%)$. Immunological workup in blood and in pleural fluid confirmed the diagnosis of systemic disease in 43 cases $(3 \%)$.

Out of the 1471 cases, the etiologies were confirmed in 1343 cases or $91 \%$ of cases. They were dominated by tuberculosis in 820 cases $(56 \%)$, of which pleurisy was isolated in $78 \%$ of cases and associated with other locations in $22 \%$ of cases ( 83 cases of mediastinal lymphadenopathy, 72 cases of parenchymal involvement, 11 cases of ascites and nine cases of 
Zaghba Nahid et al., SAS J Med, Mar, 2021; 7(3): 96-103

miliary). Neoplastic origin ranked second with 462 cases $(31 \%)$. A predominance of bronchopulmonary cancer metastasis was noted in 260 cases (18\%) followed by neo-breast metastasis in 104 cases (7\%) followed by malignant hemopathy in 25 cases and malignant pleural mesotheliom in six cases. System disease was confirmed in 43 cases (3\%), including 20 cases of lupus, 15 cases of rheumatoid arthritis and eight cases of scleroderma. The other etiologies were represented by decapitated bacterial origin in 13 cases (1\%) and Demons Meigs syndrome in 5 cases. In $9 \%$ of cases, the etiology was not known (Table-2).

According to WHO recommendations and the national tuberculosis control program in Morocco, antibacillary treatment was started in 820 patients $(56 \%)$ with tuberculous pleurisy. Patients with isolated pleural tuberculosis $(78 \%)$ received a six-month treatment according to the regimen: $2 \mathrm{RHZE} / 4 \mathrm{RH}$ comprising a two-month attack phase with four drugs: isoniazid, rifampicin, pyrazinamide and ethambutol (ERIPK4囚) according to weight, and a four-month consolidation phase with two drugs: isoniazid and rifampicin (Rhiniazide®). The nine-month regimen (2RHZE / $7 \mathrm{RH})$ was recommended in 182 patients $(22 \%)$ with pleural tuberculosis associated with other sites and the
14 patients with HIV. Chemotherapy was indicated in the 104 patients with metastatic pleurisy from a neonatal breast while curative multidrug therapy was indicated in the 25 patients with malignant hemopathy. Patients with lung cancer (18\%) received palliative treatment. A radio-chemotherapy combination was recommended in the six patients with malignant pleural mesothelioma. Systemic corticosteroid therapy was prescribed in patients with systemic disease. Antibiotic therapy with amoxicillin-clavulanic acid and fluoroquinolone was prescribed in patients with decapitated bacterial pleurisy. Symptomatic treatment based on respiratory physiotherapy and evacuating pleural punctures was indicated in all our patients, thoracic drainage was performed in 126 patients or $9 \%$ of patients with recurrent metastatic pleurisy. Pleural talcage was performed in 206 cases (14\%) of recurrent metastatic pleurisy, of which 126 cases (9\%) were under drainage and 80 cases $(5 \%)$ under thoracoscopy.

The outcome was good in 943 patients $(64 \%)$ Complications were noted in 79 cases $(5 \%)$ including 35 cases of iatrogenic pneumothorax, 31 cases of encystment and 13 cases of pachypleuritis. There were 44 deaths $(3 \%)$ and 405 patients $(28 \%)$ were lost to follow-up.

Table-1: Risk factors for serofibrinous pleurisy

\begin{tabular}{|l|l|l|}
\hline Antecedents & Number & Percent\% \\
\hline Active smoking & 501 & 34 \\
\hline History of neoplasia & 496 & 34 \\
\hline History of tuberculosis & 290 & 20 \\
\hline Tuberculosis contagion & 250 & 17 \\
\hline Diabetes & 250 & 17 \\
\hline Occupational exposure to asbestos & 132 & 9 \\
\hline Arterial hypertension & 117 & 8 \\
\hline Connectivity & 31 & 2 \\
\hline
\end{tabular}

Table-2: Different etiologies of serofibrinous pleurisy

\begin{tabular}{|l|c|c|}
\hline Antecedents & Number & Percent \% \\
\hline Tuberculosis & 820 & 56 \\
\hline Bronchopulmonary cancer metastasis & 260 & 18 \\
\hline Etiology not known & 128 & 9 \\
\hline Metastasis of the neo-breast & 104 & 7 \\
\hline System disease & 43 & 3 \\
\hline Malignant hemopathy & 25 & 2 \\
\hline Decapitated bacterial origin & 13 & 1 \\
\hline Malignant pleural mesothelioma & 6 & 0,4 \\
\hline Demons Meigs syndrome & 5 & 0,3 \\
\hline
\end{tabular}




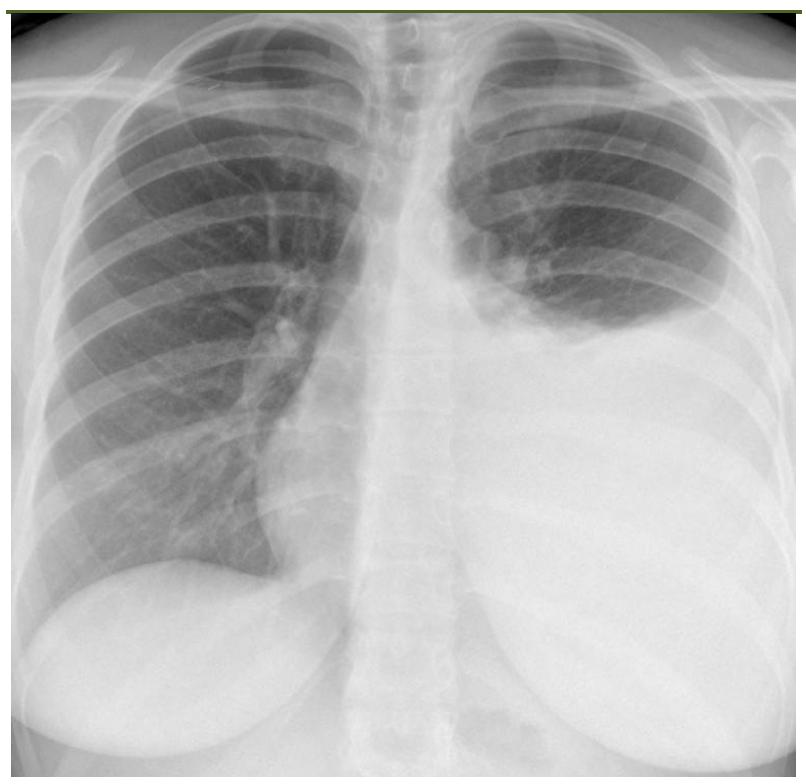

Fig-1: Chest x-ray showing left pleural type opacity

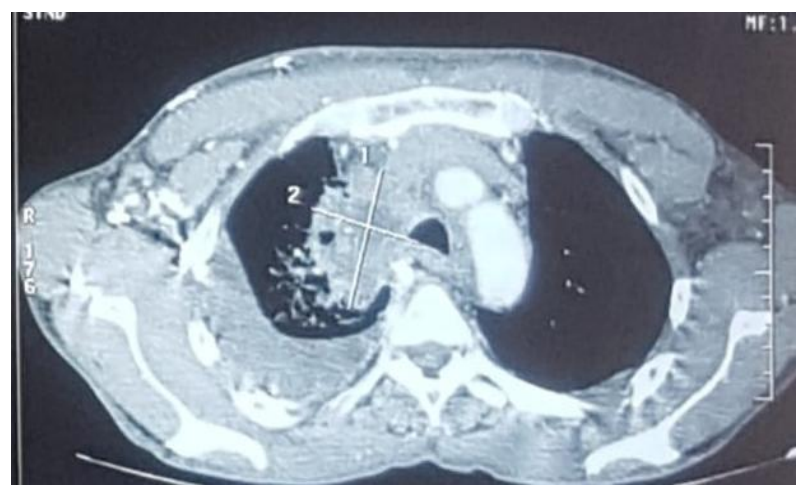

Fig-2: Thoracic CT (mediastinal window) showing right pleurisy associated with a mediastinopulmonary process

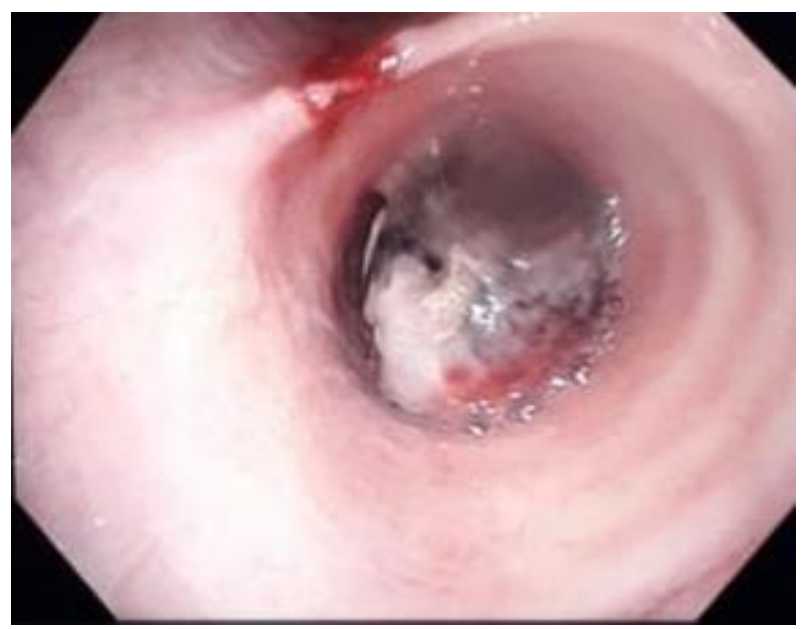

Fig-3: Endoscopic appearance of a tumor at the entrance to the left main bronchus

\section{DISCUSSION}

Serofibrinous pleurisy are pleural effusions with citrus-yellow fluid of the exudative type rich in albumin and fibrin, of variable cytological composition.
They constitute a very frequent pathology in pneumology, the etiologies of which are multiple and variable depending on the country [3]. Clinical diagnosis is easy, but careful etiological investigation is necessary. In our department, serofibrinous pleurisy represents the 1 st pathology treated with a frequency of $21 \%$. This rate is similar to that reported in a study carried out in Canada for which the rate was $21 \%$ [4]. It has been estimated at $20 \%$ in Mali [5] and 25\% in France [1]. In contrast, a Moroccan study carried out in Marrakech reported a lower rate of around $17.7 \%$ [6].

Serofibrinous pleurisy can occur at any age. In our study, the average age was 50 years with extremes ranging from 16 to 95 years. Our statistics are close to those reported in the study by N. SOUKI et al in Casablanca with an average age of 53 years [7] and those reported in the study by BEN HAMAD in Tunisia with an average age 51 years old [8].

In our series the male sex is predominant (58\%) with an $\mathrm{M} / \mathrm{F}$ sex ratio of 1.38 . This male predominance is also found in the study by H. ZAHI [9] which had $58 \%$, as well as in the study by J. El Ghoul with a rate of $57 \%$ [10].

Active smoking was noted in $34 \%$ of our patients. Tuberculosis contagion was found in $17 \%$ of cases, this rate was clearly higher than $10.3 \%$ by Diouf [11] and $11.1 \%$ by Rouijel et al., [12] who had worked on all pleurisy in the same pulmonology department. A history of treated tuberculosis was noted in $20 \%$ of cases, this figure is high compared to that reported by R.KHBAZ [13] where it is question of $2 \%$. In 14 patients $(1 \%)$, retroviral HIV serology was positive. This result was lower than the $6.3 \%$ of Diouf [11]. This finding may be due to the fact that these authors had worked on all types of pleurisy, in particular purulent.

The clinical symptomatology of pleurisy is most often made of a lateral chest pain type of side stitch which is a frequent reason for consultation and allows to discover the fluid effusion on the chest $\mathrm{x}$-ray, a dyspnea of Variable intensity depending on the pain and the extent of the effusion and a dry, quintuous cough, accentuated by changes in position [14]. In our series, $87 \%$ of our patients complained of chest pain, $83 \%$ of dry cough and $65 \%$ of dyspnea. In the majority of cases, these three cardinal signs were associated. This result is comparable to that reported by El Hassan I [15], Yena S [16] and Srivastava K [17] underlining the predominance of chest pain. Kalantri S [18] underlines the predominance of dyspnea while Valdes L [19] and Afful B [20] note the predominance of cough.

The chest X-ray shows a pleural type opacity. It has an estimated sensitivity of $70 \%$ in the diagnosis of pleural effusions [21]. In our study, radiographic examination of the chest was performed systematically on admission in all of our patients and resulted in 
unilateral pleurisy in $91 \%$ of cases and bilateral in $9 \%$ of cases. This result is comparable with that reported by Kalantari S [18], Valdes L [19] and Alaoui A [22]. The majority of effusions were judged to be of moderate abundance (71\%), matching the results reported by Alaoui A [22] while for Kalantri S [18] and Valdes L [19], pleurisy of great abundance was the majority.

Chest ultrasound confirms the diagnosis with a specificity close to $100 \%$ for pleural effusion greater than $100 \mathrm{ml}$ [23]. It makes it possible to refine the differential diagnosis, to guide a puncture in complex situations where the fluid is difficult to puncture and / or septate with less risk of complications, in particular pneumothorax [24]. Since 2010 this examination has been part of the recommendations of the BTS [25]. In our series, Chest ultrasound performed in $39 \%$ of patients, found low-abundance pleurisy in $12 \%$ of cases and encysted in $6 \%$ of cases.

When the diagnosis of pleural effusion is suspected, a pleural puncture is essential to confirm the diagnosis of pleurisy and allow analysis of the pleural fluid. The macroscopic aspect of the liquid guides the reasoning of the etiological diagnosis. Pleural puncture therefore constitutes the cornerstone of the a etiological diagnosis [26]. The punctured effusion is clear to dark citrus yellow [27]. In our series, the citrus yellow appearance was found in $89 \%$ and the light yellow appearance in $8 \%$ of cases.

The cytological study of pleural fluid is an important guiding element but is not specific [28]. In the study by Achy HV et al., 2008, analysis of the cytological formula showed lymphocytosis greater than $60 \%$ in $90 \%$ of tuberculous pleurisy in Côte d'Ivoire. Sahnsa et al., 1998 found that lymphocytosis greater than $90 \%$ in pleural fluid was strongly suggestive of tuberculous pleurisy. In our series, lymphocytosis was found in $94 \%$ of cases, a predominance of altered polynuclear neutrophils in $1 \%$ and a mixed formula in $5 \%$. Our results are consistent with the data of other authors including Alaoui et al., [22], Tobola et al., [5].

The blind pleural biopsy is the most sensitive examination. It was performed in $97 \%$ of our patients and confirmed the diagnosis in $65 \%$ of cases, a comparable rate was found in Alaoui's study A [22] and Elidrissi A [29], but it is much lower than that reported by Rakotoson J [30] and Toloba Y [5]. Blind pleural biopsy is done, as the name suggests, without eye control. Its cost-effectiveness depends on the extent of the lesions, the number of biopsy sites, the type of needle used and the experience of the operator. In tuberculosis, pleural involvement is diffuse and homogeneous, therefore its diagnostic profitability is better [31] and close to $90 \%$ [32]. However, in cases of malignant pleural involvement, blind pleural biopsy has a low diagnostic cost-effectiveness compared to thoracoscopy [33].
Thoracoscopy is the gold standard for unexplained exudate, mainly if a neoplastic cause is suspected [34]. It allows the detection of metastases which can take various macroscopic aspects. The diagnostic profitability of this technique is excellent, being $97 \%$ for neoplastic effusion, $98 \%$ for malignant pleural mesothelioma and $95 \%$ for pleural tuberculosis [35]. In our study, thoracoscopy helped to establish the etiological diagnosis in 104 patients, ie $7 \%$ of cases.

Bronchoscopy is not recommended as a firstline treatment. On the other hand, it is indicated in the presence of associated hemoptysis, atelectasis, or associated pulmonary involvement [36]. According to BOUTIN [37], this examination is an integral part of the etiological diagnostic process of an effusion plural. It would make it possible to perform bronchial biopsies and search for tuberculous fistulas. Even in the absence of endoscopic abnormalities, it would allow cytodiagnosis and bacteriological examinations to be performed on the bronchial aspiration fluid. In our context, it was performed in 401 patients $(27 \%)$ and bronchial biopsies confirmed the diagnosis in $15 \%$ of cases.

Etiologically, tuberculosis was the most frequent etiology. In our context, it represents more than half of the cases with a percentage of $56 \%$ or 820 cases. A similar finding is reported by most of the other authors, as well as in the series by Alaoui A [22] (47\%), Ndiaye E [38] (57.2\%) and El Hassane I [15] (45.4\%). While in 2nd place according to El Ghoul $\mathbf{J}$ [10] and Kalantri S [18]. The $\mathrm{KOCH}$ bacillus is only found in $1 \%$ of cases on direct examination. Culture that will give a late result is only positive $50 \%$ of the time. The most common and early diagnosis is histology, which shows a tuberculoid granuloma rich in giant cells, sometimes with caseous necrosis in its center. Pleurisy of neoplastic origin ranked second with 462 cases $(31 \%)$. Our result is consistent with that reported in a Tunisian study by ElGhoul J [10], estimated at 33\%, whereas it occupies a more important place in a Canadian series reported by Kalantri S [18] where it was estimated at $49 \%$. Bronchopulmonary and breast cancers represent the 2 main causes of secondary pleural localization with a rate of approximately $50 \%$ [39] and the 2 leading causes of cancer death. Our study matches the data in the literature, in fact, we noted the predominance of metastasis of bronchopulmonary cancer followed by metastasis of the neo-breast, which is comparable to the studies by Awashi [40] who found a predominance of metastasis of the breast bronchopulmonary cancer in $37 \%$ of cases followed by breast cancer in $25 \%$ of cases. There were 43 cases (3\%) of systemic disease including 20 cases of lupus, 15 cases of rheumatoid arthritis and eight cases of scleroderma. A similar rate has been reported by Souki $\mathrm{N}$ [7] while Alaoui [22] reports a lower rate estimated at $1.4 \%$. The etiology could not be labeled in 128 cases or 
$9 \%$. This figure remains low compared to that found in the studies of Alaoui A [22] and Ndiaye E [38] which report higher figures of $15.2 \%$ and $9.7 \%$ respectively, but it remains higher compared to the series by El Ghoul J [10] which reports a rate of $0.5 \%$ of pleurisy from undetermined causes.

The treatment of serofibrinous pleurisy must be early and adequate, it is based on symptomatic treatment and etiological treatment. Symptomatic treatment is based on respiratory physiotherapy, evacuating pleural punctures, pleural drainage (in case of recurrent neoplastic effusions) and pleural talcage by thoracoscopy or by chest drain to prevent recurrence of pleural effusion [41]. Physiotherapy is essential to ensure pulmonary re-expansion and it must be started early enough to avoid the formation of pleural adhesions [42]. All of our patients underwent respiratory physiotherapy and evacuating pleural punctures. Thoracic drainage was performed in 126 patients $(9 \%)$ and pleural talcage was indicated in 206 cases $(14 \%)$.

The etiological treatment depends on the cause of the pleurisy. In tuberculous pleurisy, the choice of therapeutic regimen varies according to the recommendations of the national tuberculosis control program (PNLAT). This regimen goes through two phases: An attack phase to quickly eliminate the majority of bacilli and to prevent the emergence of resistance to drugs by combining at least three antituberculosis drugs and a consolidation phase to eradicate them dormant bacilli. In general, fewer drugs are used. Tuberculosis treatment consists of taking several antibiotics at the same time every day for a minimum of 6 to 9 months, among the following: Isoniazid, Rifampicin, Pyrazynamide and Ethambutol [43]. In our study, two antibacillary regimens were indicated: The 2RHZE / 4RH regimen was indicated in patients with isolated pleural tuberculosis and the 2RHZE / 7RH regimen was indicated in patients with pleural tuberculosis associated with other sites and patients with HIV. The team of M.OUEDRAOGO [44] from Burkina-Faso, applied an eight-month regimen consisting of two months of ethambutol $(\mathrm{E})+$ isoniazid $(\mathrm{H})+$ rifampicin $(\mathrm{R})+$ pirazinamide $(\mathrm{Z})$ associated with six months of ethambutol $(\mathrm{E})+$ isoniazid $(\mathrm{H})$ or $2 \mathrm{RHZE}$ / $6 \mathrm{EH}$. The choice of therapeutic regimen varies depending on the relative endemic level in each country.

Treatment for neoplastic pleurisy depends on the cause (tumor) responsible for the effusion. Apart from mesothelioma, where excisional surgery has a place in a small number of highly selected cases, neoplastic pleural effusion is a formal and definitive contraindication to surgery performed for curative purposes. Treatment "of the cause" therefore relies exclusively on chemotherapy. Our patients with pleural metastasis from breast carcinoma received chemotherapy, patients with hematologic malignancy, curative multidrug therapy was indicated, and those with lung cancer received palliative treatment. The management of pleurisy as part of a systemic disease is based on short half-life oral corticosteroid therapy such as prednisone or its derivatives. It is imperative to use, the shortest duration and the minimum effective dosage. However, higher dosages are sometimes necessary (orally or as a bolus) in the event of a flare-up or in the event of extra-articular clinical manifestations. In our series, long-term corticosteroid therapy was prescribed in patients with pleurisy as a respiratory manifestation of systemic disease. In the event of decapitated purulent pleurisy, according to J. HERVE [45], there are no official recommendations for antibiotic therapy. We therefore recommend probabilistic antibiotic therapy first and then adapted in case of isolation of the germ to the data of the antibiogram. This antibiotic therapy should normally last 4 to 8 weeks. In our series, clavulanic acid amoxicillin, fluoroquinolones were indicated in 13 patients with decapitated bacterial pleurisy.

The outcome is favorable in more than $80 \%$ of cases of serofibrinous pleurisy, except for very advanced cases of the cause, especially in neoplastic pathology and also in cases of disseminated tuberculosis or very severe form in immunosuppressed conditions [1]. In the OUEDRAOGO study [44], 88\% of patients had a favorable outcome and $12 \%$ of patients died. In ONADEKO's [46], 98\% of patients had a favorable outcome with clinical improvement within one month and normalization of the chest radiography from 3 months. In our study, the outcome was favorable in $64 \%$ of cases and complications were recorded in $5 \%$ of cases.

\section{CONCLUSION}

Serofibrinous pleurisy is a frequent reason for consultation within our department, it represents $21 \%$, or about $1 / 5$ of hospitalizations. The young population, aged under 40, and the male sex are the most affected by this pathology. Clinical diagnosis is hardly a problem, but the a etiology is sometimes difficult to determine despite the variety of tests. Pleural biopsy remains an excellent diagnostic tool for tuberculous pleurisy. The etiologies of serofibrinous pleurisy remain dominated by tuberculosis being in a tuberculous endemic country, followed by neoplastic origin. Treatment is essentially based on complete evacuation of the pleural cavity, respiratory physiotherapy and a etiological treatment. In general, the course of pleurisy is most often favorable outside a neoplastic context and provided that the management is early and adequate.

Conflicts of Interest: The authors declare no conflict of interest. 


\section{REFERENCES}

1. Astoul P. Démarche diagnostique et thérapeutique devant une pleurésie. Traité de médecine Akos. 2008; 6-0685: 1-10.

2. Maskell NA, Butland RJ. BTS guidelines for the investigation of a unilateral pleural effusion in adults. Thorax. 2003;58(supplII):II8-II17.

3. Astoul P, Greillier I, Peloni JM, Fraticelli A. Méthodes d'investigation de la plèvre. Encycl Méd Chir, Pneumologie. 2005;6-000-f-55:1-15.

4. Kalantri S, Joshi R, Lokhande T, Singh A, Morgan M, Colford jr JM, Pai M. Accuracy and reliability of physical signs in the diagnosis of pleural effusion. Respiratory medicine. 2007; 101: 431-8.

5. Toloba Y, Diallo S, Sissoko BF, Kamaté B, Ouattara K, Soumaré D, Keïta B. Ponction biopsie pleurale dans le diagnostic étiologique des pleurésies. Revue des maladies respiratoires. 2011 Sep 1;28(7):881-4.

6. Kamani A. These profil epidemiologique, clinique et evolutif des pleuresies colligées au service de pneumologie au service de pneumplogie à 1'hopital militaire Avicenne Marrakech de 2010 à 2015.

7. Souki N, Choubi, M, El Khattabi W, Afif H, Aichane A, Bouayad Z. Profil étiologique des pleurésies sérofibrineuses. Revue Des Maladies Respiratoires, 31, A140. 2014.

8. Ben Hamad W, Smadhi H, Ayari A, Greb D, Ben Abdelghaffar H, Akrout I. Diagnostic étiologique d'un épanchement pleural liquidien dans un service de pneumologie en Tunisie. Rev Mal Respir. 2015 Jan; 32:A200.

9. Zahi H, El Ismaili A, El Moussaoui A. Profil étiologique des pleurésies sérofibrineuses (à propos de 251 cas). Revue Des Maladies Respiratoires, 2017; 34, A109.

10. El Ghoul J. Profil des pleurésies à liquide clair: à propos de 100 cas Service de pneumologie, Médenine, Tunisie Rev Mal Respir. 2016 Jan; 33:A257.

11. Diouf NF. Profil épidémiologique, clinique, paraclinique, étio-logique et évolutif des pleurésies à propos de 254 cas colligésà la clinique de Pneumologie du CHNU de Fann. Dakar; 2013. [Thèse de doctorat en médecine].

12. Rouijel K. Apport de la biopsie pleurale à l'aveugle dans le dia-gnostic étiologique des pleurésies exsudatives non purulenteschez les sujets séronégatifs pour le VIH. Dakar; 2010. p. 259. [Mémoire de Pneumophtisiologie].

13. Khbaz R. Les pleurésies tuberculeuses aspects épidémiologiques, clinique, paraclinique, thérapeutique et pronostique. Thèse doctorat de médecine Casablanca. 1991; 77:66.

14. Kolschmann S, Ballin A, Gillissen A. Clinical Efficacy and Safety of thoracoscopic talc Pleurodesis in malignant Pleural effusions. Chest. 2005; 128:1431-35.
15. El Hassane I, Makhloufi MT, Nafti N. Les pleurésies: étude analytique à propos de 44 cas clinique des maladies respiratoires, CHU Mustapha, Alger, Algérie. Rev Mal Respir. 2015 Jan, 32:A199-A200.

16. Sidibé A. Pleurésie au CHU du Point G: Aspects épidémiologique étiologique et thérapeutique. Thèse Méd, Bamako, 2007-2008:95.

17. Siddiqui MA, Srivastava VK. Clinical and etiological profile of patients with pleural effusion: a retrospective cross-sectional study in North India. Indian J Appl Res. 2016;6(5).

18. Kalantri S, Joshi R, Lokhande T, Singh A, Morgan M, Colford Jr JM, Pai M. Accuracy and reliability of physical signs in the diagnosis of pleural effusion. Respiratory medicine. 2007 Mar 1;101(3):431-8.

19. Valdés L, San José ME, Pose A, Gude F, González-Barcala FJ, Álvarez-Dobaño JM, Sahn SA. Diagnosing tuberculous pleural effusion using clinical data and pleural fluid analysis: a study of patients less than 40 years-old in an area with a high incidence of tuberculosis. Respiratory medicine. 2010 Aug 1;104(8):1211-7.

20. Afful B, Murphy S, Antunes G, Dudzevicius V. The characteristics and causes of pleural effusions in Kumasi Ghana: a prospective study. Tropical doctor. 2008;38(4):219-20.

21. Ruskin JA, Gurney JW. Detection of pleural effusions on supine chestadiographs. Am J Roentgenol. 1987;148:681-683.

22. Alaoui-Yazidi A. Profils cliniques et étiologiques des pleurésies, hospitalisées au service de pneumologie de l'hôpital Ibn Nafis de Marrakech de 2005 à 2009. Thèse, Marrakech, 132 pages 2011.

23. Eibenberger KL, Dock WI, Ammann ME, Dorffner R, Hörmann MF, Grabenwöger F. Quantification of pleural effusions: sonography versus radiography. Radiology. 1994 Jun;191(3):681-4.

24. Liu YH, Lin YC, Liang SJ, Tu CY, Chen $\mathrm{CH}$, Chen HJ, Chen W, Shih CM, Hsu WH. Ultrasound-guided pigtail catheters for drainage of various pleural diseases. The American journal of emergency medicine. 2010 Oct 1;28(8):915-21.

25. Havelock T, Teoh R, Laws D, Gleeson F. BTS Pleural Disease Guideline Group. Pleural procedures and thoracic ultrasound: British thoracic society pleural disease guideline 2010. Thorax, 2010;65(Suppl. 2):ii61-76.

26. Schwoebel V, Hubert B, Desenclos JC. Quel dépistage conduire auprès des personnes en contact avec un cas de tuberculose? Méd Mal Infect. 1995;25(3):377-383.

27. Villena V, López-Encuentra A, García-Luján R, Echave-Sustaeta J, Martínez CJA. Clinical implications of appearance of pleural fluid at thoracentesis. Chest. 2004;125:156-9 .

28. Clarkson B. Relationship between cell type, 
glucose concentration, and response to treatment in neoplasic effusions. Cancer. 1964;17:914928.

29. Elidrissi K. Profil clinique et étiologique des pleurésies hospitalisées au service de pneumologie de l'hôpital Ibn Nafiss, 2014. Thèse, Marrakech, 2014: 22-37.

30. Rakotoson JL, Andrianasolo RL, Rakotomizao JR, Vololontiana HM, Ravahatra K, Rajaoarifetra J, Andrianarisoa AC. Etiologies des pleurésies exsudatives: ā propos de 424 cas ā Madagascar. Pan African Medical Journal. 2011;9(1).

31. Gentina T, Tremblay A, Brichet A, Ramon P, Marquette $\mathrm{CH}$. Les biopsies pleurales à l'aveugle. Revue des maladies respiratoires. 2002;19(4):5336.

32. Bueno CE, Clemente MG, Castro BC, Martín LM, Ramos SR, Panizo AG, Glez-Río JM. Cytologic and bacteriologic analysis of fluid and pleural biopsy specimens with Cope's needle: study of 414 patients. Archives of internal medicine. 1990 Jun 1;150(6):1190-4

33. Magro P, Ferrandiere M, Hazouard E. Diagnostic des pleurésies (hors cancers). Rev Mal Resp. 2004;(21):1191- 7.

34. Koegelenberg CFN, Diacon AH. Pleural controversy: Closed needle pleural biopsy or thoracoscopy-Which first?: Closed needle biopsy or thoracoscopy? Respirology, 2011 Jul;16(5):738-746.

35. Boutin C, Rey F. Thoracoscopy in pleural malignant mesothelioma: a prospective study of 188 consecutive patients. Part 1: diagnosis. Cancer. 1993;72: 389-93.

36. Poe RH, Levy PC, Israel RH, Ortiz CR, Kallay MC. Use of fiberoptic bronchoscopy in the diagnosis of bronchogenic carcinoma. A study in patients with idiopathic pleural effusions. Chest. 1994;105:1663-7.

37. Boutin C, Viallat JR, Cargnino P, Farisse P. Thoracoscopy in Malignant Pleural Effusions 1, 2. Am Rev Respir Dis. 1981;124(5):588-592.

38. Ndiaye EM, Touré NO, Thiam K, Diatta A. Pleurésies à propos de 254 cas colligés à la clinique de pneumologie du CHNU de Fann. Rev Mal Respir. 2014 Jan, 31:A144-A145.

39. Bauwens O, Ninane V. Les nouvelles techniques diagnostiques endoscopiques. Coursdu Golf 2007 Rev Mal Respir. 2007; 27:6S28- 6S34.

40. Awasthi A, Gupta N, Srinivasan R, Nijhawan R, Rajwanshi A. Cytopathological spectrum of unusual malignant pleural effusions at a tertiary care centre in north India. Cytopathology. 2007 Feb;18(1):28-32.

41. Guitard PG, Veber B, Joly LM. Drainage thoracique aux urgences. Médecine d'urgence. 2009; 25-010-E-30: 1-11.

42. Baculard A. Conduite à tenir devant un épanchement pleural. Encycl Méd Chir, Pédiatrie. 1999;4-069-A-10:1-9.

43. Bouskraoui M, Piro Y. Prise en charge de la tuberculose chez l'enfant l'adolescent et l'adulte. 2020; 38-42.

44. Ouedraogo M, Ki C, Ouedraogo SM, Zoubga AZ, Baboum G, Zigani A. Aspects épidémiocliniques de la pleurésie sero-fibrineuse au Centre Hospitalier National Yalgado Ouedraogo. Méd. d'Afr. Noire. 2000;47:387-9.

45. Hervé J, Renaud B. Pleurésie. Encycl Méd Chir, Médecine d'urgence. 2009;25-020-C-60:1-9.

46. Onadéko BO. Tuberculous pleural effusion: clinical patterns and management in nigérians. Tubercle. 1978;59:269-75. 